\title{
Knowledge Assessment Seven Point Scale
}

\author{
Akhmet Dyussenbayev \\ Institute of physiology of man and animals of the Ministry of education and science, \\ Republic of Kazakhstan
}

\begin{abstract}
One of the most important components of the educational system is the assessment of knowledge. Nowadays there are an extreme variety of scales and slowness of the process of forming uniform world assessment standards. The model unit of measuring the quantity and quality of knowledge around the world is still missing. Today, different countries of the world use absolutely different scales of knowledge assessment in the following points: $3,4,5,6,7,10,11,12,15,20,30$ and 100 points. There is still no generally accepted objective knowledge assessment scale across the globe to be most convenient for the examiner. A universal system of objective assessment of knowledge of pupils, students and teachers is extremely necessary in the XXI century. This is an obligatory condition for the high-quality education and upbringing of the younger generation.
\end{abstract}

Keywords: scale, grade, point, sample, standard, unification, systematization, typification, classification.

For teachers in schools and universities the only way to stimulate the studying process is the assessment knowledge. Under the influence of the objective assessment, the pupil has an adequate self-assessment and a critical attitude towards himself/herself. The importance of the assessment requires looking for the number of points in the academic progress scale which would reflect the most important levels of knowledge.

In the globalized world, when young people of the third world seek to graduate from the highquality colleges and universities abroad, the unusual and completely not understandable and different scale of assessments additionally complicates the process of adaptation to the learning process.

There is no single international generally accepted system of knowledge assessment de jure and de facto in the world and, accordingly, there is no similar universal grading scale as, for instance, the units of measurement of weight: $\mathrm{kg}, \mathrm{g}$, mg or units of distance measurement: $\mathrm{km}$, $\mathrm{m}, \mathrm{dm}, \mathrm{cm}, \mathrm{mm}$ and alike. The absence of a single international grading scale creates considerable confusion and greatly complicates the integration of various states in the world educational space. 


\begin{tabular}{|c|c|}
\hline GRADING SCALES & WORLD COUNTRIES \\
\hline 0-100 points & $\begin{array}{l}\text { Bangladesh, Bahrain, Belize, Bolivia, Burundi, Guatemala, Haiti, Honduras, Zaire, } \\
\text { Zambia, Israel, India, Jordan, Iraq, Iran, Kenya, China, Costa Rica, Liberia, Mexico, } \\
\text { Myanmar, Nicaragua, Nigeria, United Arabian Emirates, Pakistan, Panama, Peru, } \\
\text { Rwanda, Saudi Arabia, Syria, Sudan, USA, Taiwan, Egypt, Ethiopia, Fiji, Philippines, } \\
\text { Sri Lanka, South Korea, Japan. }\end{array}$ \\
\hline 30 points & Italy. \\
\hline 20 points & $\begin{array}{l}\text { Venezuela, Belgium, Lebanon, Iran, Portugal, France and } 14 \text { French-speaking } \\
\text { countries in Africa. }\end{array}$ \\
\hline 15 points & Algeria, Morocco, Tunisia. \\
\hline 13 points & Denmark (before 2007). \\
\hline 0-12 points & Uruguay. \\
\hline 1-12 points & Ukraine. \\
\hline 11 points & Switzerland. \\
\hline 0-10 points & $\begin{array}{l}\text { Albania, Argentina, Armenia, Belarus, Vietnam, Greece, Georgia, India, Iceland, } \\
\text { Latvia, Macedonia, Mexico, Netherlands, Romania, El Salvador, USA, Switzerland, } \\
\text { Finland, Yugoslavia. }\end{array}$ \\
\hline 7 points & Denmark (from 2007), Finland (from 4 to 10 points). \\
\hline 6 points & $\begin{array}{l}\text { Australia, Germany, Iceland, Indonesia, Macedonia, Moldova, Norway, Poland, } \\
\text { Switzerland. }\end{array}$ \\
\hline 5 points & $\begin{array}{l}\text { Austria, Albania, Bulgaria, Bosnia and Herzegovina, Hungary, Great Britain and } 13 \\
\text { Commonwealth countries, Iran, Spain, Qatar, Cuba, Latvia, Mongolia, Serbia, } \\
\text { Thailand, Turkey, Croatia, Czech Republic. }\end{array}$ \\
\hline $\begin{array}{l}4 \text { points } \\
(2,3,4,5)\end{array}$ & $\begin{array}{l}\text { Azerbaijan, Kazakhstan, China, Kyrgyzstan, Russia, Singapore, Tajikistan, } \\
\text { Turkmenistan, Uzbekistan. }\end{array}$ \\
\hline $\begin{array}{l}3 \text { points } \\
(3,4,5)\end{array}$ & Nepal. \\
\hline
\end{tabular}

It is well-known that the first 3-point grading scale arose in the XVI century in Germany's schools. It appeared as a result of separation of all pupils into 3 numbered categories: the best "1", average" 2 " and the worst " $3 "$. With the lapse of time, the average category to which the largest number of pupils belonged was divided into classes. Thus, a 5-point scale was formed. This scale was used to assess pupils' knowledge. At that time such scale appeared because they divided only the average category ("2") into 3 sub-categories. If the best category "1" and average category "2" were divided into 3 sub-categories, in total we would have got not 5 subcategories (points) but 9 sub-categories (points). Finally, they received not full, but a partial extension of boundaries of the 3-point scale resulted in 5 points. Logically, for convenience any 9-level system becomes a 7-level classification with time since number 7 is most convenient for typification and seven-figure concepts are best remembered by the human brain. Because of convenience, the seven is also called a "magic number". It is often found in religious dogmas too. 
In Russia, Kazakhstan and other countries, a 5-point scale of assessments familiar to everyone is used. While studying the structure of optimal classification, they were convinced that the theoretical bases of typology and systematization are unified, hence their principles are universal. Assessment of knowledge of testees is also a kind of typification. During a long evolutionary process numbers 3 and 7 withstood scientific criticism, that is, three typological groups and seven types of some activity resulting from them. Three typological groups give 3 basic types and seven types are derived from them. An odd 5-point system is correct only in principle but it is imperfect, that is, truncated.

The 5-point (5-4-3-2-1) grading scale existing in some countries of the former Soviet Union is actually a 4-point scale. It is accepted formally, but in practice instead of a 5-point scale, the usual 4-point scale (5-4-3-2) is used. This is because no one gives 1 point to a pupil and this point is replaced with another unsatisfactory grade - 2 points.

\begin{tabular}{|l|l|r|c|}
\hline \multicolumn{4}{|c|}{ KNOWLEDGE PARAMETERS } \\
\hline \multicolumn{1}{|c|}{ LEVEL } & \multicolumn{1}{|c|}{ GRADE } & POINTS & PERCENT \\
\hline Extra-high & Perfect - (A) & 7 & 100 \\
\hline High & Excellent - (B) & $\mathbf{6}$ & $\sim \mathbf{9 0}$ \\
\hline Above average & Good - (C) & 5 & $\sim 70$ \\
\hline Average & Moderate - (D) & $\mathbf{4}$ & $\sim \mathbf{5 0}$ \\
\hline Below average & Satisfactory - (E) & 3 & $\sim 30$ \\
\hline Low & Poor - (F) & $\mathbf{2}$ & $\sim \mathbf{1 0}$ \\
\hline Extra-low & Bad - (G) & 1 & 0 \\
\hline
\end{tabular}

Practical teachers and researchers are looking for an alternative to the 5-point scale. One must admit that the 7-point scale of knowledge assessment is much more compact than the 10-point and more progressive than 5-point system. The 7-point gradation differs from the 5-point in the fact that it gives the examiner more chances for maneuvering criteria as it has a lot of space for selecting an adequate assessment for the actual knowledge of the testee. Teachers often face a dilemma: "5" or 4 points; " 4 " or 3 points; "3" or 2 points. It is no accident that there are such concepts as 5 points with "plus" or "minus" and alike. The 7-point scale has five positive grades: "7", "6", "5", "4", 3 points and two negative grades: "2" and 1 point. There are two low grades here: "2" and 1 point, three average grades: "5", "4" and 3 points, two high grades: "7" and 6 points. If we add only two levels to the previous 5-point scale, we can ensure shaper differentiation of the knowledge assessment. In the meantime, the scale does not become excessively cumbersome; it becomes harmonious, logically complete and classic in its style.

Perfect and complete knowledge of the subject being studied is not available to everyone, it is a lot of extra-gifted pupils. With a well-organized systematic work, a high level of academic progress can be achieved by many, but the absolute is available to very few only. The absolute values of scores are present in the 7-point grading scale being considered, which is not the case in the 5-point scale. Such scrupulousness and sharp differentiation is greatly important in the process of elementary education. As a rule, a fair assessment of the level of weak mastering a subject serves as a pledge for further success as any studies begin with a zero level. If a firstgrade pupil is familiar with the 7-point scale from the very beginning, he will not want to get such bad grades as "1" or "2" and even a passing grade - "3", but he/she should strive for higher prestigious indicators - "4" or "5" but better to "6" or "7". 
Unlike "7", grade "1" is of a dual nature since a complete lack of knowledge can be present, as a rule, not as a result of some congenital abnormalities but as a result of the lack of upbringing and education. Although there are sometimes causes of an innate nature (oligophrenia and the like). Relying on the law of conservation of matter and energy, the symmetry of the universe, the harmony of the mechanisms of nature and pendulum principle, one can state: how many geniuses, so many not. Both are an obvious minority. And most people are with average intellectual abilities and inclinations according to the normal distribution curve of GaussLaplace.

\begin{tabular}{|c|l|}
\hline POINTS & \multicolumn{1}{c|}{ LEVEL OF KNOWLEDGE } \\
\hline $\mathbf{7}$ & Outstanding level of knowledge exceeding the amount of mandatory requirements. \\
\hline $\mathbf{6}$ & Excellent level of knowledge corresponding to a full amount of mandatory requirements. \\
\hline $\mathbf{5}$ & Good level of knowledge with some inaccuracies. \\
\hline $\mathbf{4}$ & Average level of knowledge with minor mistakes. \\
\hline $\mathbf{3}$ & Satisfactory level of knowledge below average with significant mistakes. \\
\hline $\mathbf{2}$ & Poor level of knowledge with a possibility of re-sitting an exam. \\
\hline $\mathbf{1}$ & Extremely poor level of knowledge requiring the re-studying of the subject. \\
\hline
\end{tabular}

In principle, "7" could become a guiding light for the most capable pupils and an effective tool at the same time in matters relating to vocational guidance and vocational selection. But for this, the issue pertaining to school certificates should be handled first because formal "5" grades are laid in a row in them. Any mentally well developed person cannot, but rather does not, want to learn literally all subjects to the maximum. Most of them are being studied by pupils compulsorily and in such conditions the maximum is of out of the question. It's quite another matter: every pupil has his/her favorite subjects (drawing or singing lessons, mathematics or history, a foreign language or natural history). The seven is possible only if the motivation of the pupil is dominant and is multiplied by the nature's gift. In this case he/she will implement his/her abilities as far as possible. In reality, one person loves a chess club, the other person - a zoo, and the third - a stage.

Such grades as "5" and "6" are quite sufficient to reward good and diligent studies, and grade "7" can be turned into a cherished dream for the truly gifted pupils. Let us assume that a pupil has perfectly learned a poem and gets "5" for that, and if it was a lengthy fragment of the poem, he gets "6". But he/she gets seven only if he/she learned the whole poem by heart or composed good verses himself/herself. Or another example: one pupil has good drawing skills equal to grade "5", another - excellent - to grade"6", and the third - almost at the level of a professional, he/she is the one who deserves an elite grade "7". If certificates have grades " 3 " or grades " 5 " only, it is not realistic to identify ability, all the more the giftedness.

Teachers often admire - "5" with a plus! But they do not show their delight in certificates and diplomas since the scale does not allow and this is not accepted. There is a huge difference between grade "5" of a gifted pupil and grade "5" of an assiduous pupil as a talented pupil gets a high score without nervous tension, emotional shock and ordinary cramming. An experienced teacher can see this all but has to equalize them at the end of the year or semester at the same time. Ultimately, these vague grades will move to certificates and diplomas. We have in fact not " 5 " but 3-point grading scale as nobody puts "2", especially "1" in certificates or diplomas. 
One of the poorly studied aspects of our pedagogy is the influence of positive (high) and negative (low) grades on the pupil diligence as we often deal with the boomerang effect when a grade gives negative consequences instead of the expected useful result as a stimulating factor. But there is another circumstance which is much more important. During school years at the age of 7-17 the person's character is formed on the basis of his/her psycho-physiological constitution - a natural temperament and all prerequisites arise for achievement of personhood by 25 years of age. Grades being harmless in appearance affect the fragile psyche, particularly in the elementary school classes. Low grades pose a genuine dramatic effect although weak pupils hide their true state of mind. At the same time active children camouflage mental discomfort with a bright emotional reaction (indiscipline, pranks). And passive children withdraw into themselves, become reserved and acquire features of various inferiority complexes with the lapse of time. In both cases, undesirable character traits are fixed for a long time.

Since this is a really complicated problem, here the question is about the interrelation between the assessment and classification of behavior types. Assessment being a reflection of the level of knowledge while demonstrated through gradebooks, certificates, diplomas significantly affects such fragile sphere as psyche as well as the behavioral style and character of adolescents and adults. We have a paradox when adults still remember from their school years not the way they studied but what marks they got. The long-term memory stores information not about how we solved mathematical problems or wrote essays but their results in the form of a particular grade/mark. This is due to the fact that the grade is a concentrated expression of the quality of gained knowledge. Therefore, it leaves an indelible impression in the human consciousness for many years to come. In essence, each grade is a kind of a small "verdict", especially a bad or unfair grade. A grade is not only a carrot but a stick and is even worse for vulnerable and sentimental children. In extreme cases, a total hopelessness provokes adverse actions sometimes because a wrong grade is traumatic for the soul. Teachers should not underestimate children's grades due to the bad behavior of pupils or other reasons. The most optimal option is the adequacy, fairness and impartiality of grades.

\begin{tabular}{|l|l|l|c|}
\hline \multicolumn{2}{|c|}{ PUPIL'S BEHAVIOR } & POINTS \\
\hline \multicolumn{1}{|c|}{ CHARACTER TYPE } & DURING HOURS AT SCHOOL & AFTER SCHOOL & \\
\hline Expressive & Happy, careless & Easy-going, convinced & $\mathbf{7}$ \\
\hline Demonstrative & Cheerful, confident & Pushing, purposeful & $\mathbf{6}$ \\
\hline Manipulating & Vivacious, obliging & Affable, adroit & $\mathbf{5}$ \\
\hline Compromise & Sensitive, considerate & Compliant, amenable & $\mathbf{4}$ \\
\hline Tactful & & & $\mathbf{3}$ \\
\hline Judgmental & Tolerant, even & Reserved, cautious & $\mathbf{2}$ \\
\hline Depressed & Gloomy, stubborn & Secluded, solitary & $\mathbf{1}$ \\
\hline
\end{tabular}

Academic progress grades are of great practical importance. If all school subjects from the 1st to the 12th class are put in the school certificate, one can tell inclinations and abilities of the school graduate for career guidance. Points can tell about many things: whether a person has a thinking or artistic character type, whether he/she is an introvert or extrovert, whether his/her mind is an analytical or synthetic, whether his/her logic is mathematical or humanitarian, whether perception is visual or auditory, thinking is concrete: visual-figurative 
or abstract: verbal and logical and about mental type, character traits, style of behavior and personality type.

Grade is a unique key for recognizing intellectual abilities, a tool for recognizing the personality characteristics. But it is possible only in case when all grades comply strictly with the level of knowledge. The leveling is triumphant at schools. This leveling is oriented towards academic achievement in basic subjects when grades of an excellent pupil in mathematics, physics, chemistry and other disciplines are excessively inflated in minor subjects (music lesson, sports, drawing, handicraft lessons). Or vice versa, when an average pupil in the main disciplines gets his/her marks in other subjects automatically underestimated.

Recently, at the end of the school year or a term, the rating has also been applied in Kazakhstani schools according to the arithmetic mean value of the total number of points for the elapsed period. For the most accurate measurement of the result, a number of points in the scale must be odd ("3" or "5", "7" or "9", etc.) as the histogram of grades has the form of a symmetric single-humped curve of the normal Gauss-Laplace distribution. But with the existing old formally 5-point grading system, the new rating methodology turned out to be of little use. To determine the level of knowledge, the objectivity of the gained knowledge in points is first of all important but not the rating.

\section{CONCLUSIONS}

1. The systems of assessment existing in the world do not satisfy students, their parents and teachers, and this fact forces scientists to look for other grading systems. For this reason, the various systems of knowledge assessment that are currently in effect in different countries need to be re-considered in order to increase its significance and objectivity. The multi-point cumbersome grading scales used in the world practice and corresponding testing systems are very far from being ideal.

2. The goal of an ideal assessment standard is humane as such standard should stimulate a pupil with an adequate encouragement for diligence and efforts. Each newcomer will not be able to develop mentally by leaps and bounds, all the more bypassing the lower level. Talented children also walks a road from top to bottom. It is another matter how much the optimal grading scale itself contributes to it in pedagogical practice.

\section{References}

B.G. Ananiev. Pedagogical assessment psychology // Selected psychological writings: Volume II. - Moscow, 1980, $278 \mathrm{p}$.

A.R. Dyussenbayev "Classification of the types of higher nervous activity taking into account the peculiarities of thinking". Materials of Conference "Individual psychological and physiological peculiarities of human beings and professional activity". - Kiev, 1991. - pp. 93-94.

A.R. Dyussenbayev "Seven points are the optimal grading scale" // Newspaper "Teacher of Kazakhstan" - Almaty, 03.12.1992, No.21. p. 2.

A.R. Dyussenbayev "Academic progress grading system" // Magazine "Creative pedagogy". - Almaty, 2012, No. 1. p. 51-61.

A.R. Dyussenbayev “About new academic progress grading scale” // Newspaper "Teacher of Kazakhstan”, Almaty, March 2012, No.7-9 (2874). p. 6-7.

A.R. Dyussenbayev “Rating: tool or sword of Damocles?” // Magazine “Thought”. - Almaty, 2012. No. 5. p. 22-27.

A.R. Dyussenbayev "The significance of age periods and their peculiarities". Publisher: Russian Psychological Society "Psychological Newspaper". - St. Petersburg, June 21, 2012. 
A.R. Dyussenbayev (2013). "Types of temperament, character and behavior of the person. Psychological help: contents, forms, experience". Materials Ural-Volga region of the tenth seminar. Institute of consulting and training "Status". Orenburg state University, 24-27 November 2013. - Orenburg, 2014. - pp. 7-22.

N.G. Chernorukov "About experience of applying a seven point knowledge assessment system in the Nizhny Novgorod State University (NNSU) // Magazine "NNSU Messenger", Series: Innovation in education. - Nizhny Novgorod, 2003, issue 1(4).

L.R. Chitalo "Assessment system: theory issues" // Series: Public education and pedagogy. Magazine "Messenger of Adygei State University". - Maikop, 2006, Issue 2. pp 14-15. 